\title{
Influence of preliminary straining on the recovery stress in TiNi shape memory alloy working element
}

\author{
A. V. Sibirev ${ }^{\dagger}$, S. P. Belyaev, N. N. Resnina \\ †alekspb@list.ru \\ Saint Petersburg State University, St. Petersburg, 199034, Russia
}

The influence of the preliminary deformation (in the austenite state) of TiNi working elements on the peculiarities of the strain recovery and stress generation during thermal cycling was investigated. Experiments were carried out under the torsion mode with different values of the stiffness of the working element - counter body system. It is shown that, at low stiffness values $(<8 \mathrm{GPa})$, an increase in the dislocation slip stress by preliminary plastic deformation in austenite does not lead to an increase in the recovery stress. Preliminary deformation leads to an increase in the recovery stress only at a stiffness, at which the recovery stress was close to the value of the yield stress in non-deformed samples. It was found that plastic deformation in austenite led to a decrease in the values of the recovery strain due to the suppression of the reversible strain by the plastic strain. It was shown that there are no qualitative differences in the dependences of the recovery stress and recovery strain values on stiffness obtained for samples where the shape memory effect was initiated by different ways (cooling under the constant load, deformation in martensite state or cooling in the regime of the stress relaxation).

Keywords: TiNi alloy, shape memory alloys, recovery stress, martensitic transformations, thermal cycling.

УДК: 669.017 .01

\section{Влияние предварительного деформирования на генерацию реактивных напряжений рабочим элементом из сплава TiNi с памятью формы}

\author{
Сибирев А. В. ${ }^{\dagger}$, Беляев С. П., Реснина Н.Н. \\ Санкт-Петербургский государственный университет, С.-Петербург, 199034, Россия
}

В работе исследовано влияние предварительного деформирования (в аустенитом состоянии) рабочих элементов из сплава TiNi c эффектом памяти формы на особенности восстановления деформации и генерации реактивных напряжений при термоциклировании. Эксперименты были выполнены при различных значениях жёсткости системы, состоящей из рабочего тела из СПФ и упругого контр-тела. Показано, что при низких значениях жесткости (<8 ГПа) увеличение напряжения дислокационного скольжения путём предварительного пластического деформирования в аустените не приводит к увеличению реактивного напряжения. Предварительное деформирование приводит к увеличению реактивных напряжений только в том случае, если величина реактивных напряжений достигала значений близких к напряжению дислокационного течения при термоциклировании недеформированного образца. Установлено, что деформирование в аустените приводит к снижению величины эффекта памяти формы вследствие того, что пластическая деформация подавляет обратимое формоизменение. Показано, что не наблюдается качественных различий в зависимостях величин реактивного напряжения и эффекта памяти формы от жесткости, полученных для образцов, в которых эффект памяти формы был инициирован разными способами (охлаждением под постоянной нагрузкой, деформированием в мартенсите или охлаждением под релаксирующим напряжением).

Ключевые слова: сплав TiNi, сплавы с эффектом памяти формы, реактивные напряжения, мартенситные превращения, термоциклирование. 


\section{Introduction}

Shape memory alloy (SMA) actuators exhibit advantageous qualities over traditional actuators, such as low weight and volume, simple design, smooth and reliable actuation [1-7]. SMAs undergo the martensitic transformations on cooling and heating. If the transformation occurs under an external load, then SMA accumulates strain on cooling and recovers it on heating. Thus, SMAs directly transform heat into mechanical motion with a high work density (more than $\left.10 \mathrm{~J} / \mathrm{cm}^{3}\right)[1]$.

Usually, SMA actuators consist of two major parts: the SMA working body and the elastic counter-body (e.g. coil spring), which is needed to provide reverse actuation. Preliminarily deformed SMA working body on heating recovers its initial shape and simultaneously deforms the counter-body. Then on cooling the elastic counter-body in turn deforms the SMA working body again, after that the cycle repeats. Thus, actuator performance is influenced by both the working body and counter-body properties. In our previous work [8], the impact of counter-body stiffness on the recovery strain, recovery stress and work output values was studied in detail for TiNi samples preliminarily deformed in martensite or by cooling under constant stress. It was shown that the maximum recovery stress was limited by the dislocation slip stress of austenite phase. It can be assumed that to increase the recovery stress it is necessary to increase the austenite yield stress. There are different ways to increase the strength of alloys such as cold rolling, severe plastic deformation or prestraining and all of them have been successfully used to increase the recovery stress of SMAs [9-11]. However, recovery stress was generated under conditions of fully constrained strain, at the same time, the effect of the plastic hardening of the alloy on the recovery stress may depend on the stiffness of working element, counter-body system, which was never studied before. Thus, the aim of the present work was to investigate the influence of the preliminary plastic deformation on the recovery stress, recovery strain and work output values during thermal cycling of the SMA working body with different stiffness values.

\section{Materials and methods}

Cylindrical samples of $\mathrm{Ni}_{50} \mathrm{Ti}_{50}$ alloy, with a diameter of $4 \mathrm{~mm}$ and a length of $30 \mathrm{~mm}$, were water-quenched from $1173 \mathrm{~K}$ for $15 \mathrm{~min}$ and annealed at $773 \mathrm{~K}$ for $2 \mathrm{~h}$. After heat treatment, the alloy underwent the $\mathrm{B} 2 \leftrightarrow \mathrm{B} 19^{\prime}$ martensitic transformations at temperatures of $M_{s}=332 \mathrm{~K}, M_{f}=310 \mathrm{~K}$, $A_{s}=340 \mathrm{~K}$ and $A_{f}=363 \mathrm{~K}$. All experiments were performed using the testing machine designed to carry out mechanical tests in torsion mode. It consists of a pendulum dynamometer, shaft with grips for mounting sample and an electrical motor (see details in [8]). The stress value is measured by elevation angle of the pendulum lever and estimated in the outer fiber under ideal plasticity approximation as:

$$
\tau=\frac{1.5 \cdot M_{0} \sin \varphi}{\pi \cdot r^{3}}
$$

where $r$ is the sample radius, $\varphi$ is a rise angle of dynamometer lever and $M_{0}=m \cdot g \cdot h$, where $m$ is mass, attached to the dynamometer lever, $g$ - gravitational acceleration and $h$ is levers length. The shear strain is calculated in the outer fibre as:

$$
\gamma=\frac{\varphi \cdot r}{l} \cdot 100 \%
$$

where $l$ is the length of the sample.

The counter-body - SMA system stiffness was estimated as:

$$
K=\frac{1.5 \cdot l \cdot M_{0}}{\pi \cdot r^{4}} .
$$

$K$ was varied by changing the weight attached to the dynamometer lever as torsional moment $\left(M_{0}\right)$ depends on its mass $(m)$.

Recovery stress and recoverable strain variation on heating and cooling was initiated via cooling in the regime of the stress relaxation. The samples were preliminarily loaded at the temperature of $450 \mathrm{~K}$ (austenite state) up to $250 \mathrm{MPa}$, at this stage the system stiffness was the same and equal to $8 \mathrm{GPa}$, then the samples were cooled down without fixing the stress level. On cooling through the temperature range of forward martensitic transformation, the sample accumulated the strain that led to a decrease in the angle of dynamometer lever and relaxation of the stress. After cooling down to the room temperature (at which the NiTi sample was in the martensite state), another weight was attached to lever to provide different stiffness $K$ (Table 1 ). Then the sample was subjected to ten thermal cycles in the temperature range of $453 \div 300 \mathrm{~K}$. To study the influence of plastic deformation on the recovery stress, the samples were preliminarily deformed up to $10 \%$ or $20 \%$ at a temperature of $483 \mathrm{~K}$ (in the austenite state), unloaded, and all the above procedure was repeated.

Table 1. $M_{0}$ and counter-body stiffness calculated for all samples.

\begin{tabular}{|c|c|c|c|c|c|c|c|}
\hline Sample № & 1 & 2 & 3 & 4 & 5 & 6 & 7 \\
\hline$M_{0}, \mathrm{~N} \cdot \mathrm{m}$ & 3.6 & 6.7 & 12.2 & 23.2 & 34.2 & 50.7 & 61.7 \\
\hline$K, \mathrm{GPa}$ & 4.6 & 8 & 17.6 & 27.5 & 49.2 & 60.1 & 88.7 \\
\hline
\end{tabular}

\section{Results}

Fig. 1 shows the variation in stress on the first cooling (a) and on subsequent thermal cycling (b) of the sample that was not subjected to preliminary plastic deformation. It is seen that after loading, strain accumulates on the first cooling in the temperature range of the forward martensitic transformation. When strain accumulates, the stress relaxation occurs. During subsequent thermal cycling, strain recovers on heating that leads to the generation of recovery stress, and on cooling the strain accumulates which is accompanied by a stress relaxation. Recovery stress $\left(\tau^{r}\right)$ was determined as a maximum stress generated in each cycle and recovery strain value $\left(\gamma^{\mathrm{SM}}\right)$ was calculated as difference in strain values at highest and lowest temperatures in the cycle. A decrease in the recovery stress was observed in all samples during thermal cycling, for example, the dependence of recovery stress on the thermal cycle number is shown for the sample thermal cycled with stiffness of $8 \mathrm{GPa}$ in Fig. 1c. This phenomenon is due to an accumulation of irreversible strain $\left(\gamma_{\mathrm{ir}}\right)$ that decreases the recovery strain value, which is in good agreement with $[8,12]$. 
Fig. 2 shows the dependencies of the recovery strain and recovery stress values on the stiffness. It is seen that on an increase in stiffness the recovery strain value non-linearly decreases but recovery stress increases till $K<25 \mathrm{GPa}$ and remains almost constant at $K>25 \mathrm{GPa}$. The similar observations were made in [8], where it was observed that the recovery stress was constant on an increase in the stiffness higher than $34 \mathrm{GPa}$.

The influence of the prestraining on the recovery stress and recovery strain was studied for four different stiffness values: $4.6,8,49.2$ and $88.7 \mathrm{GPa}$. Table 2 shows recovery stress values obtained in the first thermal cycle in samples without prestraining and in samples subjected to preliminary deformation up to $10 \%$ or $20 \%$. It is seen that prestraining up to $10 \%$ or $20 \%$ does not influence the recovery stress if the stiffness is $4.6 \mathrm{GPa}$, and at $8 \mathrm{GPa}$ it had a limited impact. At the same time, prestraining significantly increased recovery stress values, if the stiffness values were 49.2 and $88.7 \mathrm{GPa}$. For instance, prestraining up to $20 \%$ increased the recovery stress from 245 up to $271 \mathrm{MPa}$ if the stiffness was $49.2 \mathrm{GPa}$. Thus, it may be concluded that an increase in the dislocation slip yield stress of the austenite phase allows increasing the recovery stress in the thermal cycles at high stiffness. The higher value of preliminary deformation the larger is the increase in recovery stress.

Recovery strain values obtained in the first cycle are shown in Table 3. It was observed that prestraining decreased the recovery strain values and the less stiffness the larger is the reduction in recovery strain values. A decrease in the recovery strain values may be attributed to the negative twoway shape memory effect that was induced by the oriented internal stresses formed during the preliminary deformation. In [13] it was shown that plastic strain in the austenite state decreased the recovery strain values in $\mathrm{TiNi}$ samples due to the formation of the two-way shape memory effect. To investigate this assumption, one sample was deformed in a clockwise direction up to $10 \%$ at $483 \mathrm{~K}$ and unloaded, then loaded again up to $250 \mathrm{MPa}$ in the same direction. The second sample was deformed up to $10 \%$ in the counter-clockwise direction then unloaded and loaded up to $250 \mathrm{MPa}$ in the clockwise direction. Then both samples were cooled down and subjected to two thermal cycles in the temperature range of $453 \div 300 \mathrm{~K}$ with the same stiffness of $8 \mathrm{GPa}$. This leads to the two-way shape memory effect and the shape memory

Table 2. Maximum recovery stress obtained for the samples prestrained in austenite state up to $0 \%, 10 \%$ and $20 \%$ in the first thermal cycle with various stiffness.

\begin{tabular}{|c|c|c|c|c|}
\hline$K, \mathrm{GPa}$ & 4.6 & 8 & 49.2 & 88.7 \\
\hline$\gamma_{\text {preliminary }} \%$ & \multicolumn{4}{|c|}{ Recovery stress, MPa } \\
\hline 0 & 134 & 187 & 245 & 247 \\
\hline 10 & 131 & 199 & 271 & 275 \\
\hline 20 & 139 & 200 & 294 & 292 \\
\hline
\end{tabular}

Table 3. Recovery strain value obtained in the first cycle for the samples prestrained in austenite state up to $0 \%, 10 \%$ and $20 \%$.

\begin{tabular}{|c|c|c|c|c|}
\hline$K, \mathrm{GPa}$ & 4.6 & 8 & 49.2 & 88.7 \\
\hline$\gamma_{\text {preliminary }} \%$ & \multicolumn{4}{|c|}{ Recovery strain, \% } \\
\hline 0 & 2.29 & 1.87 & 0.47 & 0.24 \\
\hline 10 & 1.78 & 1.61 & 0.46 & 0.23 \\
\hline 20 & 1.84 & 1.59 & 0.44 & 0.22 \\
\hline
\end{tabular}

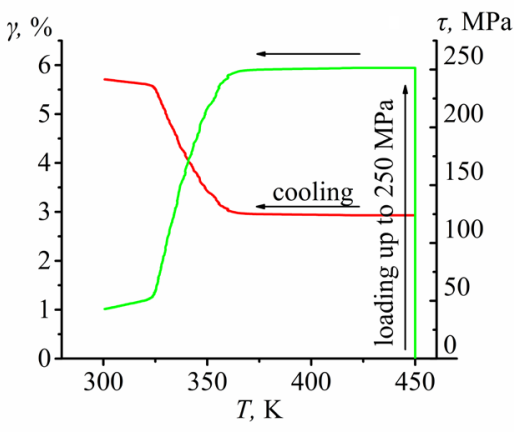

a

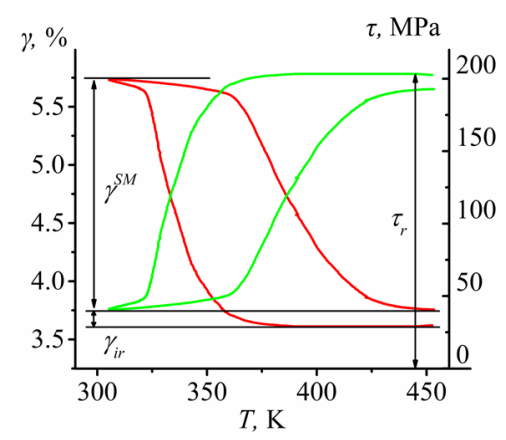

$\mathrm{b}$

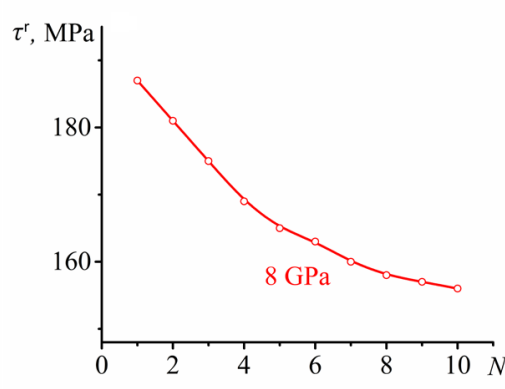

Fig. 1. (Color online) Variation in stress (green line) and strain (red line) on first cooling (a) and during thermal cycling (b) with stiffness of $8 \mathrm{GPa}$. Dependence of recovery stress on thermal cycle number (c) obtained in the sample subjected to thermal cycling with stiffness of $8 \mathrm{GPa}$.

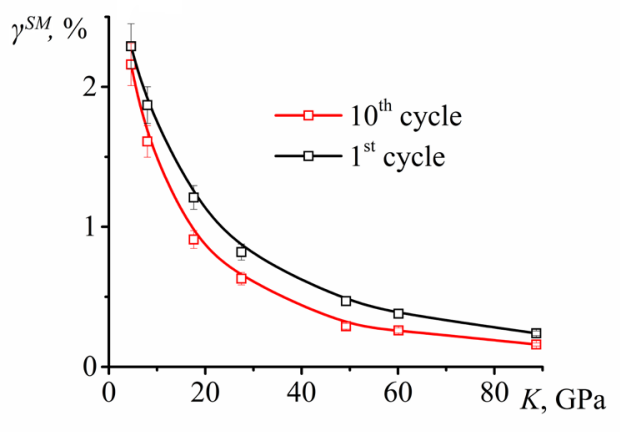

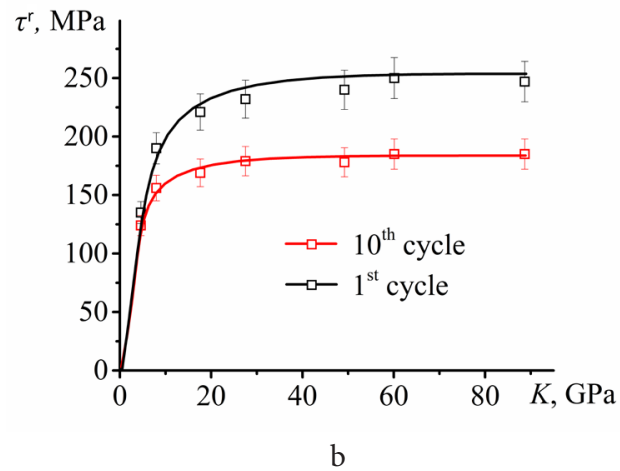

b

Fig. 2. (Color online) Dependences of the recovery strain (a) and recovery stress (b) values on stiffness $K$ obtained in first and tenth cycles. 
effect act in opposite directions in the first sample whereas, in the second sample they both act in the same direction. Therefore, in the second sample recoverable strain during the first heating should be larger than in the first sample. However, it was found that recovery strain values in both samples were the same. Thus, the two-way shape memory effect is not responsible for a decrease in the recoverable strain in the samples subjected to plastic deformation.

\section{Discussion}

The influence of preliminary deformation in the austenite state on the recoverable strain and recovery stress was investigated in TiNi torsional working elements during thermal cycling with a different stiffness. It was shown that the preliminary deformation did not influence the recovery stress if the sample was subjected to thermal cycling under a low stiffness. However, it significantly affected the recovery stress on thermal cycling under a high stiffness. This is due to the fact that preliminary straining increases the yield stress in austenite. As it was shown in [8], at low stiffness the maximum recovery stress was less than the yield stress for dislocation slip hence, its increase due to plastic hardening had no effect on the recovery stress. However, at high stiffnesses, the maximum recovery stress was limited by the dislocation slip stress [8]. So, it is obvious that an increase in the yield limit by preliminary deformation increases the recovery stress. Preliminary straining decreased the recovery strain values and the higher the stiffness, the less was the decrease in the value of recovery strain. It was shown that the twoway shape memory effect was not responsible for a decrease in the recovery strain values, thus, this may be attributed to the plastic strain suppressed strain recovery that is in a good agreement with [14]. It is also worth of noting, that in [8] the influence of the stiffness on the recovery stress and recovery strain values was studied after initiation of shape memory effect by active deformation in martensite and cooling under constant stress. In current study strain recovery was initiated by cooling in the regime of the stress relaxation; however, dependences of the recovery stress and recovery strain values on the stiffness were similar to dependencies obtained in [8]. Thus, it is shown that the way of actuator initiation does not qualitatively influence dependencies of the recovery stress and recovery strain values on the stiffness.

\section{Conclusions}

1. Preliminary plastic deformation of the TiNi samples in the austenite state increases the recovery stress during thermal cycling at high stiffness $(>8 \mathrm{GPa})$ and does not influence the recovery stress values if $K<8 \mathrm{GPa}$. This is due to the fact that the recovery stress is limited by a dislocation slip stress value in austenite state. Preliminary plastic deformation increases the yield stress for dislocation slip that allows increasing the recovery stress.

2. Preliminary plastic deformation of the TiNi samples in the austenite state decreases the recoverable strain value regardless of the stiffness value. This is due to the fact that the plastic strain partially suppresses the martensitic transformation that decreases the recoverable strain.

3. The way of the preliminary initiation of stress generation does not influence the dependences of the recovery stress and recovery strain values on stiffness or thermal cycle number.

Acknowledgements. This research was supported by the Russian Science Foundation (grant number 19-79-00106).

\section{References}

1. J. Mohd Jani, M. Leary, A. Subic, M. A. Gibson. Mater. Des. 56, 1078 (2014). Crossref

2. Y. Suzuki, Y. Kagawa. Sensors Actuators A: Phys. 292, 129 (2019). Crossref

3. Y. Kim, T. Jang, H. Gurung, N.A. Mansour, B. Ryu, B. Shin. Sensors Actuators A: Phys. 295, 512 (2019). Crossref

4. W. Huang. Mater. Des. 23, 11 (2002). Crossref

5. M. Follador, M. Cianchetti, A. Arienti, C. Laschi. Smart Mater. Struct. 21, 115029 (2012). Crossref

6. A. Hadi, H. Akbari, B. Tarvirdizadeh, K. Alipour. Sensors Actuators A: Phys. 243, 90 (2016). Crossref

7. K. Conrad, J. Choca, S. Lathers, J.T. La Belle. Crit. Rev. Biomed. Eng. 47, 121 (2019). Crossref

8. A. Sibirev, S. Belyaev, N. Resnina. Sensors Actuators A: Phys. 319, 112568 (2021). $\underline{\text { Crossref }}$

9. P. Filip, K. Mazanec. J. Mater. Process. Technol. 53, 139 (1995). Crossref

10. P. Filip, K. Mazanec. Mater. Sci. Eng. A. 174, L41 (1994). Crossref

11. Y. G. Lim, S. H. Han, E. S. Choi, W. J. Kim. Scr. Mater. 124, 95 (2016). $\underline{\text { Crossref }}$

12. P. Šittner, D. Vokoun, G. N. Dayananda, R. Stalmans. Mater. Sci. Eng. A. 286, 298 (2000). Crossref

13. S.P. Belyaev, N.N. Resnina, A.E. Volkov. Mater. Sci.Eng. A. 438 - 440, 627 (2006). Crossref

14. A. Lesota, A. Sibirev, V. Rubanik, V. Rubanik, N. Resnina, S. Belyaev. Sensors Actuators A: Phys. 286, 1 (2019). $\underline{\text { Crossref }}$ 